\title{
Research Square \\ Role of Self-esteem and Social Support on \\ Emotional Behavioral Problems Among Adolescents
}

\section{Namoode Sahar ( $\square$ namood.sahar@nip.edu.pk)}

National Institute of Psychology, Quaid-i-Azam University, Islamabad, Pakistan https://orcid.org/00000003-2086-4482

\section{Maira Saman}

Quaid-i-Azam University, Islamabad, Pakistan

\section{Yusra Sarwat}

Fazaia Education System School E-9, Islamabad, Pakistan

\section{Kiran Zaman}

Elementary School and Education Department, Lower Dir (KPK), Pakistan

\section{Research Article}

Keywords: emotional behavioral problems, self-esteem, social support, adolescents

Posted Date: March 22nd, 2021

DOl: https://doi.org/10.21203/rs.3.rs-348583/v1

License: (1) (1) This work is licensed under a Creative Commons Attribution 4.0 International License. Read Full License 


\section{Abstract}

The present study aimed to find out the role of self-esteem and social support on emotional behavioral problems among the adolescents. The sample consisted of adolescents $(N=300)$ comprising of 150 boys and 150 girls selected through purposive and convenience sampling techniques from different schools of Islamabad. All the research instruments demonstrate significant internal consistency $(r>70)$. Self-esteem and social support were found to have a significant negative correlation with emotional behavioral problems (EBP) such as increased self-esteem and social support could significantly decrease EBP among adolescents as hypothesized. Regression analysis also supported the association and demonstrated that study variables account for about $23 \%$ of variance in EBP. Findings of the study can be applied for introduction of programs to increase the self-esteem and improve the social support in order to minimize the emotional behavioral problems among the adolescents.

\section{Introduction}

Behaviors as delusions and lack of affect are marked examples of the extreme behavioral disturbances in seriously emotionally disturbed students. EBD may be explained by biological factors; such as genetics, brain damage or dysfunction, malnutrition and allergies, temperament, or physical illness, family factors; such as the family definition and structure, family interaction, family influences on school success and failure, and external pressures affecting families, and school factors; such as deficiencies in the ability of school personnel to accommodate students' variable intelligence, academic achievement, and social skills (Kauffman,1997). To study the role of social support and self-esteem in these emotional behavior problems among adolescents is the aim of our research.

\section{Emotional-Behavioral Problems}

An emotional and behavioral disturbance is an emotional disability characterized by inability to build or maintain satisfactory interpersonal relationships, inability to learn which cannot be adequately explained by intellectual, sensory or health factors, consistent inappropriate type of behavior or feelings under normal conditions, displayed pervasive mood of unhappiness or depression and displayed tendency to develop physical symptoms, pains or unreasonable fears associated with personal or school problems (Forness \& Knitzer, 1992).

Emotional Disturbance is a disability characterized by behavioral or emotional responses in school so different from appropriate age, cultural, or ethnic norms and affect educational performance (National Mental Health and Special Education Coalition, 2003).

According to the International Debate Education Association (IDEA), emotional disturbance includes schizophrenia but does not apply to children who are socially maladjusted, unless it is determined that they have an emotional disturbance (American Psychiatric Association, 2000). 
Complicating matters of emotional-behavioral disturbances is identified of more males, African Americans, and those who are economically disadvantaged than one would find statistically in the population. Students with EBD are generally divided into two subcategories: those with externalizing behavior and those with internalizing behavior. Externalizing behavior includes aggression, disruption, and other forms of acting out; internalizing behavior includes such problems as depression, anxiety, and social withdrawal, in which the primary difficulty is private or internal. The most frequent problems observed by teachers are externalizing. However, internalizing problems can be debilitating, and students can have both types of problems, showing both types at the same time or alternating between the two. This may lead to special problems of adolescence which include delinquency, substance abuse, and early sexual activity, anxiety, depression, and schizophrenia. The main contributing factor found to be was lack of social support and a false low perception about the self (U.S. Department of Education, 1998).

\section{Theories of emotional-behavioral disturbances.}

Psychodynamic model. This Model was proposed by Freud (1896). The definition for the psychodynamic model considers the emotionally disturbed child to be so halted in satisfaction of their needs for safety, affection, acceptance, and self-esteem that they are unable intellectually to function efficiently, cannot adapt to reasonable requirements of social regulation and convention, or is so plagued with inner conflict, anxiety, and guilt that they are unable to perceive reality clearly or meet the ordinary demands of the environment in which they live.

ABCDE model of emotional disturbance. Albert Ellis and Windy Dryden (1987) proposed that people developed irrational beliefs in response to preferential goals being blocked. He set this up in an ABCDE model. "A" stands for Activating Event or Adversity. This is any event. It is just a fact. " $\mathrm{B}$ " refers to one's Irrational Belief about the event at "A." That belief then leads to "C," the emotional and behavioral Consequences. " $D$ " stands for disputes or arguments against irrational beliefs. E stands for New Effect or the new, more effective emotions and behaviors that result from more reasonable thinking about the original event. (Ellis \& Dryden, 1987)

\section{Social Support}

Social support is a feedback provided via contact with similar and valued peers (Gottlieb, 1985). Support systems help the individual mobilize his psychological resources and master his psychological, emotional burdens; they share his tasks; and they supply him with extra supplies of money, materials, tools, skills, and cognitive guidance to improve his handling of his situation (Caplan, 1974). Feedback from a primary group that is health protective, during times of stress is also referred to as social support (Cassel, 1976).

Types of social support. There are four common functions of social support. Emotional support is the offering of empathy, concern, affection, love, trust, acceptance, intimacy, encouragement, or caring. It is the warmth and nurturance provided by sources of social support. Providing emotional support can let the individual know that he or she is valued. It is also referred to as "esteem support" or "appraisal 
support." Tangible support is the provision of financial assistance, material goods, or services. Also called instrumental support, this form of social support encompasses the concrete, direct ways people assist others. Informational support is the provision of advice, guidance, suggestions, or useful information to someone. This type of information has the potential to help others problem-solve. Companionship support is the type of support that gives someone a sense of social belonging. This can be seen as the presence of companions to engage in shared social activities.

\section{Theories of social support.}

Theory of reasoned action. The theory of Reasoned Action was developed by Fishbein and Ajzen (1980). It discusses attitudes toward reference groups and subjective perceptions of norms, which is especially relevant to appraisal and feedback types of social support. Reasoned Action is explicitly concerned with behavior. However, this theory also recognizes that there are situations or factors that limit the influence of attitude on behavior. For example, if our attitude leads us to want to go out on a date but we have no money, our lack of money will prevent our attitude from causing us to go on a date. Therefore, Reasoned Action predicts behavioral intention, a compromise between stopping at attitude predictions and actually predicting behavior. Specifically, reasoned action predicts that behavioral intent is created or caused by two factors: our attitudes and our subjective norms.

Health belief model. This model was first developed in the 1950 s by social psychologists Hochbaum, Rosenstock, and Kegels. The model was developed in response to the failure of a free tuberculosis (TB) health screening program. Since then, the HBM has been adapted to explore a variety of long- and shortterm health behaviors. According to this model other people provide information, encouragement to undertake, or refrain from recommended actions. Membership in social groups provides context for beliefs and perceptions (Rosenstock, 1974).

Social learning theory. In social learning theory Bandura (1977) states that behavior is learned from the environment through the process of observational learning. The social environment is the context in which people observe new behavior and evaluate the implications directly or vicariously of new behavior. Social Learning theory also talks about the reinforcement. Reinforcement can be external or internal and can be positive or negative. Another important term coined by Social learning theory is Identification. Identification is different to imitation as it may involve a number of behaviors being adopted whereas imitation usually involves copying a single behavior.

Ecological system theory. This theory is formulated by famous psychologist Bronfenbrenner (1979). According to this model group membership provides a context in which behavior can be encouraged or discouraged and a means for interpreting acceptable behavior. This theory helps us to understand why we may behave differently when we compare our behavior in the presence of our family and our behavior when we are in school or at work. So the ecological systems theory holds that we encounter different environments throughout our lifespan that may influence our behavior in varying degrees. 
Diffusion of innovation theory. It is expressed by Rogers (1983) in his publication 'Diffusion of Innovations'. It proposed that better communication and information flow within groups that share common characteristics that act as a characteristic of change agent. According to this theory earlier adopting individuals tend not to be different in age, but to have more years of education, higher social status and upward social mobility, be in larger organizations, have greater empathy, less dogmatism, a greater ability to deal with abstractions, greater rationality, greater intelligence, a greater ability to cope with uncertainty and risk, higher aspirations, more contact with other people, greater exposure to both mass media and interpersonal communications channels and engage in more active information seeking.

\section{Self-Esteem}

The "esteem" part of self-esteem comes from the Latin word aestimare, meaning to value and the "self" part is self-explanatory, referring to you, yourself. So think of self-esteem as how you value yourself. Selfesteem is a personal judgment of the worthiness that is expressed in the attitudes the individual holds towards himself (Coopersmith, 1967). It is the judgments that we make about our own self-worth and the feelings associated with those judgments (Berk, 2003; Fleming \& Courtney, 1984). Self-esteem has been found to be multi-faceted with general self-esteem containing an umbrella of separate self-esteems such as academic competence, close friendship, appeal job competence and physical appearance (Harter, 1999; LeMare, Ditner, \& Woody, 1999). It can also be referred to as self-worth or self-image and is the global dimension of self (Santrock, 2005).

\section{Theories of self-esteem.}

Sociometry theory. It is proposed by Leary and Downs (1995). The sociometery theory depicts selfesteem as an internal gauge designed to monitor individuals' successes in interpersonal relationships, particularly the degree to which they are being included or excluded from social groups, and to motivate corrective actions when one's level of social inclusion gets dangerously low. It also highlights that Selfesteem is not a unitary construct, but rather a collection of internal representations, monitoring mechanisms, updating mechanisms, evaluative mechanisms motivational mechanisms, and mechanisms designed to generate behavioral output. This theory presented reconceptualization of selfesteem and self-esteem motivation, suggesting that the self-esteem system is an internal, psychological gauge that monitors the degree to which the individual is being included versus excluded by other people. Self- esteem, then, is an internal representation of social acceptance and rejection. The sociometer perspective provides a framework for understanding the extensive literature on self-esteem, as well as the link between self-esteem and emotional and behavioral problems. Leary also has been studying the negative emotional and behavioral effects of self-reflection as well as processes that may counteract the "curse" of the self.

Self-determination theory (SDT). The theory was initially developed by Deci and Ryan (1985). It states that man is born with an intrinsic motivation to explore, absorb and master his surroundings and that true high self-esteem is reported when the basic psychological nutrients or needs of life (i.e., relatedness, 
competency and autonomy) are in balance. According to this theory when social conditions provide support and opportunity to fulfill these basic needs, personal growth, vitality and well-being are enhanced. It is a theory of motivation, concerned with supporting our natural or intrinsic tendencies to behave in effective and healthy ways.

According to this theory people are centrally concerned with motivation, how to move themselves or others to act. Everywhere, parents, teachers, coaches, and managers' struggle with how to motivate those that they mentor, and individuals struggle to find energy, mobilize effort and persist at the tasks of life and work. People are often moved by external factors such as reward systems, grades, evaluations, or the opinions they fear others might have of them. Yet just as frequently, people are motivated from within, by interests, curiosity, care or abiding values. These intrinsic motivations are not necessarily externally rewarded or supported, but nonetheless they can sustain passions, creativity, and sustained efforts. The interplay between the extrinsic forces acting on persons and the intrinsic motives and needs inherent in human nature is the territory of this theory.

Terror management theory (TMT). Terror management theory (TMT), first proposed by Rosenblatt, Greenberg, Solomon, Pyszczynski, and Greenberg (1989) suggests that people adhere to cultural worldviews and beliefs in order to suppress death and mortality-related thoughts. Additionally, TMT suggests that individuals must feel that they are significant contributors to this worldview and derive their sense of self-esteem according to whether or not they meet culturally determined standards (Pyszczynski, Solomon \& Greenberg, 2003). According to this theory self-esteem is seen as a culturally based construction derived from integrating specific contingencies valued by society into ones' own 'worldview'. Theory paints a somewhat morbid picture high self-esteem promotes positive affect and personal growth, psychological well-being and coping as a buffer against anxiety in the knowledge of our eventual certain death, and reduces defensive anxiety related behavior.

\section{Literature Review}

Liu, Kurita, Sun, and Wang (1999) carried out a study on a Chinese sample of 1695 children between the ages of 6-11 years. Chinese adolescents with elevated depressive symptoms and behavioral problems were found to suffer from low self-competence and depleted social support, which in turn can lead to isolation, substance abuse, somatic complaints and suicidal ideation. Specifically, in this study it was examined whether negative attachment cognitions predicted depression and anxiety symptoms, and emotional behavioral disorders.

Van der Wolf and Strobel (2001) in a cross-national study compared and examined the relationship between social-emotional and school functioning in American and Dutch adolescents. In this study, data was collected from early adolescents (ages 12 to 14 years). Researchers compared adolescents' selfreported emotional-behavioral problems, general self-esteem, and their sense that negative moods interfered with their ability to learn in school across the two samples. It was found that American youth reported more internalizing and externalizing problems than did their Dutch peers, and said that negative moods interfered more with their ability to learn in school. The study also examined the relative predictive 
relations between adolescents' social-emotional functioning and motivation to learn and their reported investment in or disaffection from school. Both sets of indices predicted investment in both samples, although the pattern of significant relations differed by country. Findings were discussed in relation to a broader model of the social, demographic, and psychological processes that shape patterns of academic investment or disaffection, achievement, and choice during the adolescent years. They found academic efficacy to be positively correlated with self-esteem (US and Dutch samples) but negatively correlated with emotional behavioral problems as assessed by Youth Self-Report (YSR) of Child Behavior Checklist (CBCL).

Heitlich and Goodman (2004) research on children with respect to specific cultural and socio demographic background that should also be taken into account while determining the risk and protective factors of child psychopathology in any community. Thus it was determined by this research that the community is major factor among the factors contributing in the disturbances among children.

Chirkou, Ryan, Kim and Kaplan suggested that social conditions provide support and opportunity to fulfill basic needs, personal growth, vitality and well-being. Higher the social conditions higher the personal growth and the emotional behavioral well-being. (La Guardia, Ryan, Couchman, \& Deci, 2000; Ryan \& Deci, 2004). Similarly, Mikulincer, Florian and Hirschberger, after study on adolescents of age 10-16 reached the conclusion that high self-esteem promotes positive affect and personal growth, psychological wellbeing and coping as a buffer against anxiety in the knowledge of our eventual certain death, and reduces defensive anxiety related behavior. (Pyszczynski et al., 2004)

Barkmann and Schulte-Markwort (2005) studied the prevalence and causal factors of emotional and behavioral problems in children and adolescents in Germany. Self-report and parental rating on $\mathrm{CBCL}$ (Child Behavior Checklist) was used. The sample consisted of 1950 children and adolescents of ages 418. The prevalence rate was found to be between $10-18 \%$ in children and adolescents. The main causal factors found to be low level of self-esteem and a lack of parent peer support, which results into school drop outs and even in the growing suicidal ideation among the adolescents. Goldman (2009) studied that lack of social support leads to the low self-esteem among adolescents and which may lead to emotional behavioral disturbances in a number of cases. If emotional-behavioral problems are left undiagnosed, scholastic performance, social interactions, and life skills are affected.

Connell (2009) studied the causes and prevention of emotional and behavioral disorders among children and adolescents. He was using research to develop interventions for at-risk children and youth. In particular, his work had focused on refining our understanding of family processes related to the risk for depression in youth, and on developing a family-focused intervention for depressive disorders in youth. So the lack of family support could lead to disturbances among adolescents (Schubert Center for Child Studies, 2009). Another study with a sample of 5053 (Saleem \& Mahmood 2011) school children highly significant correlation was between emotional disturbances and the social factors.

Literature also identified many psychosocial factors that may become risk factors for developing emotional and behavioral problems of children as studied by Muris, Mayer, Reinders, and Wesenhagen, 
(2011). Also, Soomro and Clarbour, (2012) investigated the relationship between emotional behavior and academic achievement in middle school children in Hyderabad, Pakistan. Results of the research revealed academic achievement to be negatively associated with malevolent aggression, but positively related to social self-esteem. In addition, mediator analysis indicated social self-esteem to partially mediate the relationship between malevolent aggression and academic achievement.

\section{Rationale of Study}

In Pakistan 43\% of the population is below 15 years (Federal Bureau of Statistics, 2011). Awareness about the children and their mental health problems remains neglected in this developing society therefore very few systematic studies have been carried out in Pakistan to address this crucial and important issue of social support, self-esteem, emotional and behavioral problems in adolescents. Various groups have estimated percentages of behaviorally disordered and emotionally disturbed children ranging from $1-40 \%$ of the school-age population. These disturbances were attributed as the consequence of self-defeating because of irrational or distorted perceptions. Students were studied in this regard and when they were taught to challenge their irrational beliefs asserted that thinking affects, and in some ways creates, individuals' feelings and behaviors; their emotions have an important impact on their thoughts and actions, and their actions distinctly influence their thoughts and feelings. Consequently, if one of these processes is somehow altered, the others are influenced as well. (Zionts, 1996).

The purpose of this research is to study the role of the society that is behind the increasing emotionalbehavioral disturbances and the decreasing self-esteem in our adolescents. It also highlights the important definitions of emotional-behavioral problems and the self-esteem. In past many researches, studies and surveys are done to determine the role of society on the emotional-behavioral disturbances and also on the self-esteem of both children and adolescence. But the core focus of our research is to find out the relationship of role of society on emotional-behavioral problems and self-esteem in adolescents and how all these three variables are interrelated with one another. We hope this research will be proved very useful for the society in order to control the growing problems among our adolescents.

\section{Method}

\section{Objectives}

1. To find out relationship between social support, emotional behavioral disturbances and self-esteem among adolescents.

2. To study impact of social support on emotional behavioral disturbances and self-esteem among adolescents.

\section{Hypothesis}


1. Social support is negatively correlated with emotional disturbances among adolescents.

2. Social support is positively correlated with self-esteem among adolescents.

3. Higher level of self-esteem will decrease emotional and behavioral problems among adolescents.

\section{Instruments}

Selfesteem Scale. This scale was first developed by Rosenberg (1965). For the current study, it is translated to Urdu. While designed as a Guttman scale, the SES is now commonly scored as a Likert scale. 10 items are answered on a four point scale ranging from strongly agree to strongly disagree. Testretest correlations are typically in the range of .82 to .88 , and Cronbach's alpha for various samples are in the range of .77 to .88 (Blascovich \& Tomaka, 1993; Rosenberg, 1986). To score the items, values are assigned to the 10 items as follows:

- For items 1, 3, 4, 7, 10: Strongly Agree=3, Agree=2, Disagree=1, and Strongly Disagree=0.

- For items 2, 5, 6, 8, 9 (which are reversed): Strongly Agree=0, Agree=1, Disagree=2, and Strongly Disagree $=3$.

The scale ranges from 0-30, with 30 indicating the highest score possible. Other scoring options are possible. For example, one can assign values 1-4 rather than 0-3; then scores will range from 10-40. Some researchers use 5- or 7-point Likert scales, and again, scale ranges would vary based on the addition of "middle" categories of agreement.

Social Support Scale. This scale is 12-item measure of perceptions of social support. This measure is a shortened version of the original ISEL (40 items; Cohen \& Hoberman, 1983) and is translated into Urdu for the current study. This questionnaire has three different subscales designed to measure three dimensions of perceived social support. These dimensions are appraisal support, belonging support, and tangible support. Each dimension is measured by 4 items on a 4-point scale ranging from definitely true to definitely false. To score this scale the values are assigned as follows:

- Items 1, 2, 7, 8, 11, 12 are reverse scored.

- Items 2, 4, 6, 11 make up the Appraisal Support subscale

- Items 1, 5, 7, 9 make up the Belonging Support subscale

- Items, 3, 8, 10, 12 make up the Tangible Support subscale

Emotional Behavioral Disturbances Scale. This scale was first developed by Schniering, and Rapee (2002). For the current study, it was translated to Urdu. Each subscale is scored by summing up the 
relevant responses; such as lowest being 0 and highest being 4 . Subscales have a range of $0-40$. The total score is the sum of all subscales (range $0-160$ ).

Physical Threat: 4, 7, 9, 12, 16, 20, 24, 33, 36, 39.

Social Threat: 1, 6, 8, 14, 18, 21, 25, 29, 31, 32 .

Personal Failure: $3,11,13,17,23,26,28,30,34,38,2,5,10,15,19,22,27,35,37,40$.

\section{Sample}

The sample of adolescents was approached at secondary schools of Islamabad with the permission of school authorities. It consisted of 150 girls and 150 boys i.e., the total sample was of 300 adolescents. The age range was 11-18 years $(M=15)$. Participants provided demographic information including gender, age, family system and income of family.

\section{Procedure}

Sample was approached with the permission of school authorities and with the consent of adolescents themselves through informed consent. Firstly they were informed about the nature and purpose of the study. Other ethics were also taken into account i.e. adolescents were given their right of confidentiality and privacy. They also had the right to withdraw from the research at any time. The research began by giving the participants a brief introduction and the necessary instructions to fill the questionnaire. The participants were seated comfortably while answering the questionnaire. Finally, participants were debriefed and thanked.

\section{Results}

\section{Table 1}

Descriptive Statistics for all Variables $(N=300)$ 


\begin{tabular}{|lll|}
\hline Scales & $M$ & $S D$ \\
\hline Self esteem & 17.60 & 4.28 \\
\hline Appraisal support & 8.50 & 2.81 \\
\hline Belonging support & 7.13 & 2.64 \\
\hline Tangible support & 8.14 & 2.60 \\
\hline Social support & 23.77 & 5.98 \\
\hline Physical threat & 8.46 & 6.47 \\
\hline Social threat & 8.19 & 6.55 \\
\hline Personal failure & 21.81 & 10.07 \\
\hline Emotional Behavioral Problems & 38.37 & 20.96 \\
\hline
\end{tabular}

Table 1 shows descriptive statistics for all the variables involved in the present study i.e., self-esteem, social support and emotional behavioral problems. Mean $(M)$ indicates the average score of each instrument for the present sample $(N=300)$. Standard Deviation $(S D)$ indicates the deviation in scores for each instrument. Self-esteem scale was used to assess the level of self-esteem among adolescents. Social support scale was used to assess social support among adolescents. Appraisal support, belonging support and tangible support are the subscales of Social Support scale. Emotional Behavioral Problem Scale was used to assess emotional behavioral problems among adolescents. Physical threat, social threat and personal failure are the subscales of this scale.

\section{Table 2}

Reliability Co-efficient of all the Study Scales $(N=300)$

\begin{tabular}{|lllr|}
\hline Scales & Subscales & No. of Items & $a$ \\
\hline Self esteem & & 10 & .60 \\
\hline Social Support & & 12 & .62 \\
\hline & Appraisal support & 4 & .47 \\
\hline & Belonging support & 4 & .42 \\
\hline & Tangible support & 4 & .40 \\
\hline Emotional Behavioral Problems & & 40 & .90 \\
\hline & Physical threat & 10 & .77 \\
\hline & Social threat & 10 & .82 \\
\hline & Personal failure & 20 & \\
\hline
\end{tabular}


Table 2 shows that all the scales including self-esteem, social support and emotional behavioral problem scales have high alpha coefficient of reliability. The subscales of social support i.e., appraisal support, belonging support, tangible support and that of emotional behavioral problem scale i.e., physical threat, social threat, and personal failure also show moderate reliability. This shows that the instruments have good internal consistency

\section{Table 3}

Inter-scale Correlations Between the Study Variables $(N=300)$

\begin{tabular}{|lllllllllll|}
\hline & & 1 & 2 & 3 & 4 & 5 & 6 & 7 & 8 & 9 \\
\hline 1. & SE & - & .10 & .14 & .11 & $.15^{\star \star}$ & -.14 & $-.17^{\star \star}$ & $-.21^{\star \star}$ & $-.16^{\star \star}$ \\
\hline 2. & ASS & - & - & $.38^{\star \star}$ & $.38^{\star \star}$ & $.80^{\star \star}$ & $-.20^{\star \star}$ & $-.26^{\star \star}$ & $-.20^{\star \star}$ & $-.23^{\star \star}$ \\
\hline 3. & BSS & - & - & - & $.22^{\star \star}$ & $.72^{\star \star}$ & $-.16^{\star \star}$ & $-.24^{\star \star}$ & $-.17^{\star \star}$ & $-.20^{\star \star}$ \\
\hline 4. & TSS & - & - & - & - & $.71^{\star \star}$ & $-.19^{\star \star}$ & $-.21^{\star \star}$ & $-.16^{\star \star}$ & $-.20^{\star \star}$ \\
\hline 5. & SST & - & - & - & - & - & $-.25^{\star \star}$ & $-.32^{\star \star}$ & $-.24^{\star \star}$ & $-.29 \star \star$ \\
\hline 6. & PT & - & - & - & - & - & - & $.65^{\star \star}$ & $.73^{\star \star}$ & $.86^{\star \star}$ \\
\hline 7. & ST & - & - & - & - & - & - & - & $.79 \star \star$ & $.89 \star \star$ \\
\hline 8. & PF & - & - & - & - & - & - & - & - & $.95^{\star \star}$ \\
\hline 9. & EBD & - & - & - & - & - & - & - & - & - \\
\hline
\end{tabular}

$* \star p<.01$

Table 3 shows that self-esteem has a negative correlation with emotional behavioral problems, also the social support has a significant negative correlation with emotional behavioral problems. Self-esteem and social support is positively correlated but the relation is not significant.

\section{Table 4}

Effect of Self-esteem and Social Support on Emotional Behavioral Problems ( $N=300)$ 


\begin{tabular}{|lccccc|}
\hline \multicolumn{5}{|c|}{ Emotional Behavioral Problems } \\
& \multicolumn{7}{c|}{$\underline{95 \% \mathrm{Cl}}$} \\
\hline Self-esteem & -.17 & .27 & -.03 & -.37 & .70 \\
\hline Social Support & -.54 & .20 & -.29 & -1.44 & -.67 \\
\hline & & $R=.41, R^{2}=.25, \Delta R^{2}=.23(F=33.26 * \star$ \\
\hline
\end{tabular}

$\star \star p<.001$

Table 4 shows the regression analysis which indicates that the independent variables self-esteem and social support jointly accounted for $23 \%$ of variance in emotional behavioral problems among adolescents. It indicates that self-esteem and social support are negative predictors of Emotional Behavior Problems; social support being the significant one. This supports the hypothesis that: "Selfesteem is negatively correlated with emotional behavioral problems among adolescents" and "Social support is negatively correlated with emotional problems among adolescents".

\section{Discussion}

The purpose of present study is to find the relationship between self-esteem, social support and behavioral disturbances among adolescents and how these three variables are inter-related. The instruments used for the present study are self-esteem scale, social support scale and emotional behavioral disturbance scale. Table 1 shows descriptive statistics including the mean and standard deviations for all the variables involved in the present study i.e., self-esteem, social support and emotional behavioral problems.

Table 2 shows that all the scales including self-esteem, social support and emotional behavioral problem scales have high alpha coefficient of reliability. The subscales of social support i.e., appraisal support, belonging support, tangible support and that of emotional behavioral problem scale i.e., physical threat, social threat, and personal failure also show moderate reliability. This shows that the instruments have good internal consistency

Table 3 shows that there is a negative correlation among social support and emotional behavioral problems. This supports "Social support is negatively correlated with emotional problems among adolescents" and the results are supported by the previous research by Roth \& Cohen (1986) that addresses several coping strategies regarding emotional behavioral problems among the children including appraisal, problem solving and seeking social support. It showed a significant negative correlation between the coping strategies and the emotional behavioral problems. Another study showed that low self-esteem has been linked with a number of emotional and behavioral problems (Leary, Schreindorfer \& Haupt, 1995). It indicated that compared to teenagers with high esteem, those with low 
self-esteem tend to be more anxious, depressed, lonely, jealous, shy and generally unhappy. Table 3 also shows that there is a negative correlation between self-esteem and the emotional behavioral problems, supporting the hypothesis "Self-esteem is negatively correlated with emotional behavioral problems among adolescents" and the research findings are supported by the previous research findings by (Silverstone, \& Salsali, 2003) in which teenagers were studied on the self-report inventory including 100 statements. The findings showed that Low self-esteem has been shown to be correlated with a number of negative outcomes, such as depression and other emotional behavioral problems among the teenagers. Another study (Saleem \& Mahmood 2013) on 1500 school children showed a predominance of internalizing problems expressed as anxiousness, withdrawal, feeling of rejection and somatic problems making major contribution to academic problems and low self-esteem. The role of personal and familial factors in emotional behavioral problems was also highlighted. This also supported both of our hypotheses that were accepted on the basis of the results shown by Pearson product moment correlation.

Table 4 shows the regression analysis on the independent variables self-esteem and social support and the dependent variable of emotional behavioral disturbances. It indicates that self-esteem and social support are negative predictor of the emotional behavioral disturbances; social support being the significant one. This result is supported by the previous research on adolescents underlying the protective role of social support, coping strategies, self-esteem, and social activities on experience of stress, depression and other emotional behavioral problems (Dumont \& Provost, 1999). Findings revealed that well-adjusted adolescents had higher self-esteem and were characterized by good social support and coping strategies.

\section{Conclusions}

It is thus concluded that social support is negatively associated with emotional behavioral problems among adolescents and also that the self-esteem is negatively correlated with the emotional behavioral problems among the adolescents.

\section{Limitations And Suggestions}

1. The limitations of this study may include its small sample size. For further studies larger sample should be taken so that the results become generalized.

2. Purposive and convenience sampling techniques were used for the selection of sample. For more generalizable results, random sampling may be used.

3. Another limitation can be shortage of time in which the research has been conducted.

\section{Implications of Present Study}


This study shows that self-esteem and social support has a negative correlation with the emotional behavioral problems among adolescents, so by introducing certain programs in order to increase the selfesteem and improve the social support among the adolescents the emotional behavioral problems can be minimized.

\section{Declarations}

\section{Statement on Conflict of Interest}

Authors of the study have no conflict of interest to report

\section{References}

Ajzen, I., \& Fishbein, M. (1980). Understanding attitudes and predicting social behavior. Englewood Cliffs, NJ: Prentice-Hall.

Banks, T., \& Zionts, P. (2009). Teaching a cognitive behavioral strategy to manage emotions rational emotive behavior therapy in an educational setting. Intervention in School and Clinic, 44(5), 307-313.

Deci, E. L., \& Ryan, R. M. (1985). Intrinsic motivation and self-determination in human behavior. New York: Plenum.

Dumont, M. \& Provost, M. A. (1999). Resilience in adolescents: Protective role of social support, coping strategies, self-esteem, and social activities on experience of stress and depression. Journal of Youth and Adolescence, 28(3): 343-363.

Forness, S. R., \& Knitzer, J. (1992). A new proposed definition and terminology to replace serious emotional disturbance in Individuals with Disabilities Education Act. School Psychology Review, 21(1): $12-20$.

Freud, S. (1896). Heredity and the etiology of the neuroses. In Standard edition (Vol. 3, pp. 142-156).

Glaser, B. \& Strauss, A. (1967). The discovery of grounded theory: Strategies forqualitative research. Chicago: Aldine.

Goldenberg, J., Pyszczynski, T., Greenberg, J., \& Solomon, S. (2000). Fleeing the body: A terror management perspective on the problem of human corporeality. Personality \& Social Psychology Review, 4(3): 200-218.

Grisso, T., Vincent, G., \& Seagrave, D. (Eds.). (2005). Mental health screening and assessment in juvenile justice. Guilford Press.

Henley, M., Ramsey, R. S., \& Algozzine, R. F. (1999). Teaching students with mild disabilities (4th ed.). Boston: Pearson. 
Hepper, E. G., \& Carnelley, K. B. (2012). The self-esteem roller coaster: Adult attachment moderates the impact of daily feedback. In Personal Relationships. Southampton: University of Southampton.

Kauffman, J. M. (1997). Characteristics of emotional and behavioral disorders of children and youth. Prentice Hall: Merrill

Leary, M. R., \& Tangney, J. P. (Eds.). (2003). Handbook of self and identity. New York: Guilford Press.

Leary, M. R., Schreindorfer, L. S., \& Haupt, A. L. (2004). The Role of Low Self-Esteem in Emotional and Behavioral Problems: Why Is Low Self-Esteem Dysfunctional? In R. M. Kowalski \& M. R. Leary (Eds.), Key readings in social psychology. The interface of social and clinical psychology: Key readings (p. 116128). Psychology Press.

Lium, X. C., Ma, D. D, Kurita, H., \& Tang M. Q. (1999). Self-reported depressive symptoms among Chinese adolescents.Social Psychiatry and Psychiatric Epidemiology, 34:44-47.

Rogers, E. M. (1983). Diffusion of Innovations (3rd Ed.). New York: The Free Press

Rosenstock, I. (1974). Historical origins of the health belief model. Health Education Monographs, 2(4): 328-335.

Rutherford, R. B., Quinn, M. M., \& Mathur, S. R. (Eds.). (2004). Handbook of research in emotional and behavioral disorders (Vol. 642). New York: Guilford Press.

Smith, D. D. (2007). Introduction to Special Education: Making a Difference (pp. 236-242) Retrieved from: www.education.com/reference/article/emotional-behavioral-disorders-defined/ 